Jurnal Ekonomi dan Industri

e-ISSN: 2656-3169

Volume 21, No.3, September-Desember 2020

p- ISSN: 0853-5248

\title{
PENGARUH LINGKUNGAN KERJA DAN MOTIVASI KERJA TERHADAP KINERJA KARYAWAN PT BINTANG KEMAKUMURAN CABANG HANKAM BEKASI
}

\author{
Shintya Nur Aini ${ }^{1)}$ \\ 1) Mahasiswa Program Studi Manajemen FE UNKRIS \\ Freddrick Tiagita $\mathbf{P}^{2}$ ) \\ 2) Dosen Program Studi Manajemen FE UNKRIS \\ Alamat: Kampus UNKRIS, Jatiwaringin Jakarta Timur \\ Email: freddricktiagitaputra@gmail.com
}

\begin{abstract}
Along with the changing times, company leadership must be able to bring the company to be more developed and able to compete in changing times. In this case, company leaders must find the right strategy to achieve the goals they have set. To achieve a goal requires effective and efficient employee performance. Several factors can improve employee performance through the work environment and work motivation. This research was conducted to determine whether there is an influence of work environment and work motivation on employee performance simultaneously or partially at PT Bintang Kemakmuran cabang Hankam-Bekasi. This research method was conducted with 42 respondents, data were collected using a questionnaire with a Likert scale. The test results showed that the work environment and work motivation simultaneously had a significant effect on employee performance. In addition, the work environment and work motivation partially also have a significant effect on employee performance.
\end{abstract}

Keywords: Work environment, work motivation, employee performance

\section{PENDAHULUAN}

Sumber daya manusia merupakan faktor penting yang menentukan keberhasilan suatu perusahaan. Sumber daya manusia yang dimiliki perusahaan harus dapat membawa perusahaan menjadi semakin berkembang dan mampu bersaing dalam perubahan zaman yang ada. Dalam hal ini pemimpin perusahaan harus menemukan strategi yang tepat guna untuk mencapai tujuan yang ditetapkannya. Salah satu strategi yang dapat digunakan perusahaan adalah dengan manajemen sumber daya manusia.

Manajemen sumber daya manusia pada dasarnya merupakan upaya mengelola orangorang dalam suatu perusahaan guna mencapai tujuan yang ditetapkannya. Perusahaan yang dijalankan harus memiliki kinerja karyawan yang dapat melaksanakan tugas-tugasnya dengan cara yang efektif dan efisien. Tanpa kinerja karyawan yang optimal, tujuan perusahaan tidak akan dicapai sesuai yang diharapkan. Masalah yang terjadi pada kinerja karyawan akan sangat berpengaruh dan berdampak langsung bagi perusahaan. Oleh karena itu, perusahaan dituntut untuk meningkatkan kualitas sumber daya manusia sehingga menyebabkan terjadinya peningkatan kinerja karyawan.

Seiring dengan berkembangnya kemajuan jaman maka sarana transportasi menjadi salah satu hal penting yang dibutuhkan masyarakat dalam melakukan berbagai aktifitas. Di Indonesia terdapat beberapa perusahaan alat transportasi yang bersaing secara ketat. Terdapat beberapa merk alat transportasi yang ada di indonesia seperti Suzuki, Honda, Yamaha dan Kawasaki melakukan persaingan untuk mendapatkan pangsa pasar. PT Bintang Kemakmuran Bekasi yang berlokasi di kecamatan Pondok Melati dan telah berdiri 
sejak tahun 2005 menjadi salah satu perusahaan di Indonesia yang bergerak dibidang otomotif dengan menjual alat transportasi sepeda motor dengan merk Honda dan menyediakan jasa service. PT Bintang Kemakmuran adalah dealer resmi sepeda motor Honda yang berada dibawah meandealer Jawab Barat yang bernama PT Daya Adi Cipta Mustika (pusat dealer Jawa Barat) yang berada di Bandung.

PT. Bintang Kemakmuran melakukan penilaian secara periodik terhadap kinerja karyawan untuk mengetahui sejauh mana pencapaian kinerja seluruh karyawan. Hal tersebut dilakukan karena mangingat kinerja karyawan sangat berhubungan erat dengan pendapatan yang diperoleh perusahaan. Namun setelah dilakukan pengumpulan beberapa data, menunjukan indikasi adanya kinerja karyawan yang tidak memenuhi target perusahaan.

Dalam peningkatan pelayanan konsumen perusahaan dihadapi dengan permasalahan kinerja karyawan yang menurun. Fenomena ini terjadi karena kualitas hasil kerja yang kurang baik seperti terdapat beberapa komplain konsumen, kuantitas kerja yang tidak tercapai dengan tepat waktu dan ketepatan waktu dalam pengiriman pembelian sepeda motor. Faktor-faktor tersebut mengakibatkan banyaknya konsumen yang membatalkan pembelian sehingga mengakibatkan penurunannya target penjualan dalam PT Bintang Kemakmuran.

Dengan demikian yang diindikasi mempengaruhi kinerja karyawan di PT. Bintang Kemakmuran adalah lingkungan kerja dan motivasi kerja. Lingkungan kerja yang dirasakan oleh karyawan terdiri atas fisik dan nonfisik. Lingkungan kerja dengan pencahayaan yang cukup, sirkulasi udara yang baik, kebersihan yang terjaga serta jauh dari kebisingan akan memberikan kenyamanan karyawan dalam bekerja. Lingkungan kerja nonfisik yang meliputi sikap saling menghargai diwaktu berbeda pendapat, keramahan antara karyawan merupakan beberapa hal yang seharusnya dirasakan para karyawan dalam membina kinerja secara terus menerus. Lingkungan kerja yang baik dan dapat membuat karyawan merasa nyaman dapat mendukung aktivitas karyawan dalam bekerja.

Hasil wawancara yang penulis lakukan, lingkungan kerja di PT. Bintang Kemakmuran dinilai kurang baik dalam mendukung aktivitas karyawan dalam bekerja. Terdapat beberapa faktor yang membuat kondisi lingkungan kerja di dikantor dealer PT. Bintang Kemakmuran menjadi tidak ideal seperti pencahayaan yang tidak memenuhi standar karena jumlah yang tidak sesuai dengan kondisi ruangan. Sirkulasi udara yang kurang baik karena ruangan yang tidak terlalu besar diisi oleh beberapa divisi dan tidak didukung dengan jumlah AC yang cukup. Kebersihan yang tidak terjaga karena petugas kebersihan tidak bekerja maksimal. Kurangnya keamanan dilingkungan kerja karena tidak adanya security. Kebisingan yang diakibatkan oleh suara bising yang berasal dari bengkel Honda yang letaknya bersebelahan menjadi. Walaupun hubungan karyawan dan kerjasama karyawan sudah cukup baik, tetapi saat jam kerja menunjukkan pukul 13.00 keatas karyawan akan merasa sedikit jenuh dan kantor akan terasa sepi. karena karyawan disaat setelah jam istirahat terlihat mengantuk dan cendurung sibuk dengan kegiatannya masingmasing seperti bermain handphone, sehingga menjadikan kinerja karyawan menurun.

Selain faktor lingkungan kerja, kurangnya motivasi kerja karyawan yang disebabkan karena kebutuhan fisik untuk karyawan masih kurang memadai seperti tempat beristirahat untuk karyawan PT Bintang Kemakmuran, kebutuhan rasa aman dan keselamatan kerja untuk para karyawan masih kurang adanya jaminan kesehatan dan keselamatan dalam bekerja , kebutuhan bersosial yang sangat kurang untuk saling membantu satu sama lain, kebutuhan akan penghargaan atau reward sulit didapatkan walaupun kinerja karyawan yang dilakukan oleh karyawan sudah meningkat dan mencapainya target, serta kebutuhan 
wujudan diri yang didapatkan oleh karyawan terkadang tidak sesuai dengan pencapaian yang telah dilakukan. Faktor-faktor tersebut menyebabkan karyawan tidak mematuhi beberapa peraturan yang telah ditetapkan perusahaan, seperti dalam hal kehadiran.

Salah satu peran penting yang harus ditekankan oleh suatu perusahaan agar dapat mencapai tujuannya adalah dengan memperbaiki lingkungan kerjanya dan meningkatkan motivasi kerja para karyawan. Karena lingkungan kerja adalah segala sesuatu yang ada disekitar para pekerja yang dapat mempengaruhi dirinya dalam menjalankan tugas-tugas yang dibebankan. Selain itu, motivasi merupakan hal sangat penting bagi suatu perusahaan atau organisasi. Motivasi kerja ini memiliki pengaruh bagi para karyawannya untuk melakukan pekerjaannya.

Adapun tujuan penelitian ini adalah untuk mengetahui apakah lingkungan kerja dan motivasi berpengaruh terhadap kinerja karyawan PT Bintang Kemakmuran Cabang Hankam Bekasi

\section{LANADASAN TEORI}

\section{Kinerja Karyawan}

Menurut Mangkunegara (2017) Kinerja pada karyawan adalah hasil kerja secara kualitas dan kuantitas yang dicapai oleh seorang pegawai dalam melaksanakan tugasnya sesuai dengan tanggung jawab yang diberikan kepadanya.

Indikator kinerja yang digunakan dalam penelitian ini adalah menurut. Rahmawanti, et al, (2014): 1). Kualitas; Kualitas kerja diukur dari persepsi karyawan terhadap kualitas pekerjaan yang dihasilkan serta kesempurnaan tugas terhadap keteram pilan dan kemampuan karyawan. 2). Kuantitas; Merupakan jumlah yang dihasilkan dinyata kan dalam istilah seperti jumlah unit, jumlah siklus aktivitas yang diselesaikan. 3). Ketepatan waktu; Merupakan tingkat aktivitas diselesaikan pada awal waktu yang dinyatakan, dilihat dari sudut koordinasi dengan hasil output serta memaksimalkan waktu yang tersedia untuk aktivitas lain.

\section{Lingkungan Kerja}

Sedarmayanti (2015) mengungkapkan Kondisi dan suasana lingkungan kerja yang baik akan dapat tercipta dengan adanya penyusunan organisasi secara baik dan benar sebagaimana yang secara garis besar lingkungan kerja dibagi menjadi 2 yaitu fisik dan non fisik. Semua keadaan yang terjadi yang berkaitan dengan hubungan kerja, baik kondisi, situasi, hubungan kerja dengan atasan maupun dengan sesama rekan kerja, ataupun dengan bawahan.

Pengukuran lingkungan kerja menggunakan indikator dari Sedarmayanti (2015), Indikator lingkungan kerja secara fisik yaitu: 1). Pencahayaan. 2). Sirkulasi udara. 3). Kebersihan. 4). Keamanan. 5). Kebisingan.

Lingkungan Kerja non fisik yaitu: 1). Hubungan atasan dengan bawahan, yaitu sejauh mana karyawan merasakan adanya komunikasi yang baik, terbuka, dan lancar, baik antara teman sekerja ataupun dengan pimpinan. 2). Kerja sama karyawan, yaitu sejauh mana karyawan merasakan ada kerjasama yang baik diantara kelompok kerja yang ada.

\section{Motivasi Kerja}

Menurut Hasibuan (2013) menyatakan bahwa motivasi kerja adalah pemberian daya penggerak yang menciptakan kegairahan seseorang, agar mereka mau bekerja sama, bekerja efektif dan terintegrasi dengan segala daya upayanya untuk mencapai kepuasan. 
Sedangkan menurut Maslow yang dikutip oleh Hasibuan (2013) bahwa motivasi kerja karyawan, adapun indikator-indikator untuk mengetahui tingkat motivasi pada karyawan, yaitu: 1). Kebutuhan fisik. 2). Kebutuhan rasa aman dan keselamatan. 3). Kebutuhan sosial. 4). Kebutuhan akan penghargaan. 5). Kebutuhan perwujudan diri.

\section{METODE PENELITIAN}

\section{Rancangan Penelitian}

Penelitian yang dilakukan pada penelitian ini menggunakan teknik analisis data kuantitatif. Penelitian kuantitatif ini dipilih karena berguna untuk mengetahui seberapa besar pengaruh lingkungan kerja dan motivasi kerja terhadap kinerja karyawan pada PT Bintang Kemakmuran Cabang Hankam Bekasi. Metode pengumpulan data dalam penelitian ini menggunakan data primer dengan menyebarkan kuesioner.

Populasi dalam penelitian ini adalah karyawan PT Bintang Kemakmuran Cabang Hankam Bekasi yaitu sebanyak 42 orang. Adapun teknik pengambilan sampel yang digunakan dalam penelitian ini adalah sampling jenuh sebanyak 42 orang, berdasarkan pada ketentuan Arikunto (2012) jumlah sampel diambil secara keseluruhan apabila jumlah populasi keseluruhan kurang dari 100 orang.

Pengujian hipotesis yang dilakukan dalam penelitian dengan metode regresi linier sederhana dan berganda. Secara umum analisis regresi linier sederhana dan berganda menurut Ghozali (2016) adalah analisis yang dilakukan untuk mengetahui ada atau tidaknya pengaruh suatu hubungan antara dua variabel yaitu variabel independen dan variabel dependen . Perhitungan rumus linier berganda sebagai berikut:

$$
Y=a+b_{1} X_{1}+b_{2} X_{2}
$$

Sebelum dilakukan pengujian hipotesis, maka dilakukan terlebih dahulu pengujian instrument data dengan melihat validitas data dan reliabilitas data, kemudian dilanjutkan pengujian asumsi dasar dan asumsi klasik.

\section{HASIL PENELITIAN DAN PEMBAHASAN}

\section{Analisis Hasil Penelitian}

\section{Hasil Uji Validitas dan Uji Reliabilitas}

Variabel penelitian yang terdiri dari lingkungan kerja, motivasi kerja, dan kinerja keseluruhan memiliki 39 butir pernyataan. Validitas merupakan derajat ketepatan antara data yang terjadi pada objek penelitian dengan data yang dapat dilaporkan oleh peneliti. Pada uji validitas digunakan untuk mengukur yang dapat dikatakan sah atau tidaknya suatu kuesioner (Sugiyono, 2017). Berdasarkan uji validitas terdapat 14 butir pertanyaan untuk lingkungan kerja, 10 butir pertanyaan untuk motivasi kerja, 16 pertanyaan butir untuk kinerja dengan hasilnya dinyatakan valid.

Pengujian reliabilitas diperlukan untuk menguji seberapa jauh hasil pengukuran yang dapat diandalkan secara konsisten. Pada tabel-1, hasil pengujian reliabilitas menunjukkan bahwa nilai Cronbach's Alpha semua variabel dalam penelitian ini lebih besar dari 0.6, sehingga penelitian ini dapat dianggap reliabel. 
Tabel-1: Hasil Uji Reliabilitas

\begin{tabular}{lccc}
\hline \multicolumn{1}{c}{ Variabel } & $\begin{array}{c}\text { Cronbach } \\
\text { Alpha }\end{array}$ & $\begin{array}{c}\text { Nilai kritis } \\
(\boldsymbol{\alpha})=\mathbf{5 \%}\end{array}$ & Keterangan \\
\hline Lingkungan Kerja & 0.928 & 0.600 & Reliabel \\
Motivasi Kerja & 0.809 & 0.600 & Reliabel \\
Kinerja Karyawan & 0.939 & 0.600 & Reliabel \\
\hline
\end{tabular}

Sumber: Data Primer, diolah tahun 2020

\section{Uji Asumsi Dasar dan Klasik}

\section{Hasil Uji Normalitas}

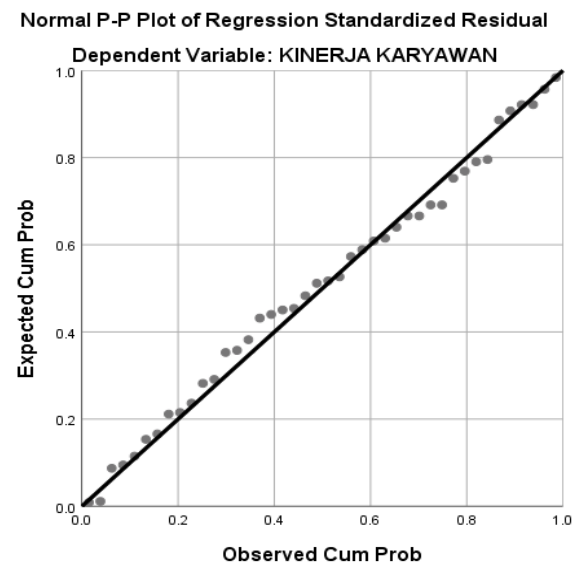

Gambar 1. Normal Probability Plot

Sumber: Data primer yang diolah, 2020

Berdasarkan gambar diatas, maka dapat disimpulkan bahwa probability plot menggambarkan data mendekati normal, dimana terlihat adanya titik-titik yang mendekati garis diagonal dan mengikuti arah garis diagonal tersebut. Uji normalitas baik dengan menggunakan tabel Kolmogorov-Smirnov maupun grafik P-Plot menyatakan bahwa data penelitian ini terdistribusi secara normal.

\section{Hasil Uji Linieritas}

Berdasarkan perhitungan ANOVA dapat dilihat bahwa nilai signifikansi kurang dari 0,05 yang berarti terdapat hubungan yang linier signifikan antara lingkungan kerja dan motivasi kerja terhadap kinerja karyawan PT Bintang Kemakmuran Cabang HankamBekasi.

\section{Hasil Uji Multikolinieritas}

Berdasarkan perhitungan koefisien regresi maka dapat disimpulkan bahwa nilai tolerance lebih dari 0,01 dan VIF kurang dari 10. Dengan demikian, pada model 1 regresi ini tidak ditemukan adanya korelasi antar variabel bebas atau dapat dikatakan tidak terjadi multikolinieritas. 


\section{Hasil Uji Heterokedastisitas}

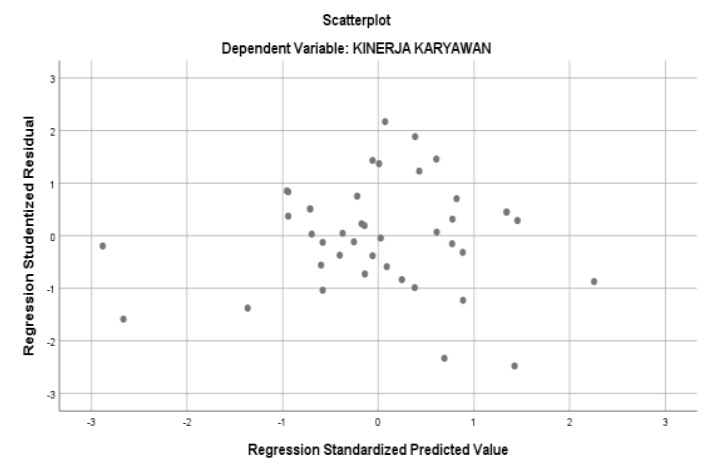

Gambar2. Scatter Polt

Sumber: Data primer yang diolah, 2020.

Berdasarkan pada gambar scatterplot di atas, dapat dilihat bahwa antara SRESID dan ZPRED dimana sumbu Y adalah Y yang telah diprediksi dari X adalah residual (Y prediksi dengan $\mathrm{Y}$ sesunngguhnya) yang menunjukkan adanya titik-titik menyebar secara acak, tidak membentuk sebuah pola tertentu yang jelas dan tersebar dengan baik di atas maupun dibawah angka 0 pada sumbu Y. Maka dari itu berdasarkan pada grafik diatas, dapat disimpulkan bahwa pada model regresi ini tidak terjadi heteroskedastisitas.

\section{Hasil Analisis Regresi Linear Sederhana}

Tabel-2: Pengaruh Lingkungan Kerja Terhadap Kinerja Karyawan

\begin{tabular}{lccccc}
\hline \multirow{2}{*}{ Variabel } & $\begin{array}{c}\mathbf{R} \\
\text { Square }\end{array}$ & Konstanta & $\begin{array}{c}\text { Koefisien } \\
\text { Regresi }\end{array}$ & Sig & $\boldsymbol{\alpha}$ \\
\hline Lingkungan_Kerja & 0.482 & 3.913 & 0.360 & 0.000 & 0.05 \\
\hline Pengujian Signifikan & & & & & \\
\hline t hitung $>$ t tabel $=5.727>2.021$ & & & & \\
\hline
\end{tabular}

a. Dependent Varible: Kinerja

Sumber: Data primer yang diolah, 2020.

Persamaan regresi yaitu sebagai berikut: $\mathrm{Y}=3.913+0.360 \mathrm{X}_{1}$

Berdasarkan tabel-2, nilai koefisien determinasi $\left(\mathrm{R}^{2}\right)$ sebesar 0.482 , artinya lingkungan kerja memberikan kontribusi sebesar $48.2 \%$ kepada kinerja karyawan PT Bintang Kemakmuran Cabang Hankam Bekasi, sedangkan sisanya sebesar $51.8 \%$ disumbangkan faktor lain yang tidak diteliti. Lingkungan kerja berpengaruh positif terhadap kinerja karyawan PT Bintang Kemakmuran Cabang Hankam Bekasi, sebesar 0.360, artinya jika ada peningkatan lingkungan kerja, maka kinerja karyawan PT Bintang Kemakmuran Cabang Hankam Bekasi akan meningkat atau sebaliknya. Nilai t-hitung lebih 
besar dari t-tabel $(5.727>2.021)$ atau dengan melihat nilai signifikansi yang diperoleh yaitu $(0.000<0.05)$, hal ini berarti bahwa Ho tolak, Ha terima, artinya lingkungan kerja berpengaruh signifikan pada tingkat nyata 95\% terhadap kinerja karyawan PT Bintang Kemakmuran Cabang Hankam Bekasi.

Tabel-3: Pengaruh Motivasi Kerja Terhadap Kinerja Karyawan

\begin{tabular}{lccccc}
\hline \multirow{2}{*}{ Variabel } & $\begin{array}{c}\mathbf{R} \\
\text { Square }\end{array}$ & Konstanta & $\begin{array}{c}\text { Koefisien } \\
\text { Regresi }\end{array}$ & Sig & $\boldsymbol{\alpha}$ \\
\hline Motivasi Kerja & 0.365 & 5.993 & 0.476 & 0.000 & 0.05 \\
\hline Pengujian Signifikan & & & & \\
\hline t hitung > t tabel = 4.425 > 2.021 & & & & \\
\hline a. Dependent Varible: Kinerja \\
Sumber: Data primer yang diolah, 2020.
\end{tabular}

Persamaan regresi yaitu sebagai berikut: $\mathrm{Y}=5.993+0.476 \mathrm{X}_{2}$

Berdasarkan tabel-3, nilai koefisien determinasi $\left(\mathrm{R}^{2}\right)$ sebesar 0.365 , artinya motivasi kerja memberikan kontribusi sebesar $36.5 \%$ kepada kinerja karyawan PT Bintang Kemakmuran Cabang Hankam Bekasi, sedangkan sisanya sebesar 64.5\% disumbangkan faktor lain yang tidak diteliti. Motivasi kerja berpengaruh positif terhadap kinerja karyawan PT Bintang Kemakmuran Cabang Hankam Bekasi sebesar 0.476, artinya jika ada peningkatan motivasi kerja, maka kinerja karyawan PT Bintang Kemakmuran Cabang Hankam Bekasi akan meningkat atau sebaliknya. Nilai t-hitung lebih besar dari t-tabel $(4.425>2.021)$ atau dengan melihat nilai signifikansi yang diperoleh yaitu $(0.000<0.05)$, hal ini berarti bahwa Ho tolak, Ha terima, artinya motivasi kerja berpengaruh signifikan pada tingkat nyata 95\% terhadap kinerja karyawan PT Bintang Kemakmuran Cabang Hankam Bekasi.

\section{Hasil Analisis Regresi Linear Berganda}

Tabel-4: Pengaruh Lingkungan Kerja dan Motivasi Kerja Terhadap Kinerja Karyawan

\begin{tabular}{lccccc}
\hline \multirow{2}{*}{ Variabel } & $\begin{array}{c}\text { R- } \\
\text { Square }\end{array}$ & Konstanta & $\begin{array}{c}\text { Koefisien } \\
\text { Regresi }\end{array}$ & Sig. & $\boldsymbol{\alpha}$ \\
\hline $\begin{array}{l}\text { Lingkungan_Kerja } \\
\text { Motivasi_Kerja }\end{array}$ & 0.655 & 5.053 & 0.293 & 0.000 & 0.05 \\
\hline Pengujian Signifikan & 0.343 & 0.000 & 0.05 \\
\hline F-hitung > F tabel = 37.039>3.238 & & & \\
\hline a. Dependent Varible: Kinerja \\
Sumber: Data primer yang diolah, 2020.
\end{tabular}

$$
\text { Persamaan regresi; } \mathrm{Y}=5.053+0.293 \mathrm{X}_{1}+0.343 \mathrm{X}_{2}
$$

Berdasarkan tabel-4, nilai F-hitung lebih besar dari F-tabel $(37.039$ > 3.238) atau dengan melihat nilai signifikansi sebesar 0.000 yang berarti lebih kecil dari nilai probabilitas 0.05 atau $(0.000<0.05)$, maka Ho tolak, Ha terima, artinya lingkungan kerja 
dan motivsi kerja secara bersama-sama berpengaruh signifikan pada tingkat nyata 95\% terhadap kinerja karyawan PT. Bintang Kemakmuran Cabang Hankam Bekasi. Nilai koefisien determinasi $\left(\mathrm{R}^{2}\right)$ sebesar 0.655 , artinya lingkungan kerja dan motivasi kerja secara bersama-sama memberikan kontribusi sebesar $65.5 \%$ kepada kinerja karyawan PT. Bintang Kemakmuran Cabang Hankam Bekasi, sedangkan sisanya sebesar $34.5 \%$ disumbangkan faktor lain yang tidak dibahas dalam penelitian ini.

Lingkungan kerja dan motivsi kerja berpengaruh positif dan signifikan terhadap kinerja karyawan PT. Bintang Kemakmuran Cabang Hankam Bekasi pada tingkat nyata 95\%. Koefisien lingkungan kerja sebesar 0.293, artinya jika ada peningkatan lingkungan kerja, maka kinerja karyawan PT. Bintang Kemakmuran Cabang Hankam Bekasi akan meningkat atau sebaliknya dengan asumsi motivasi kerja tidak berubah. Koefisien motivasi kerja sebesar 0,343, artinya jika ada peningkatan motivasi kerja, maka kinerja karyawan PT. Bintang Kemakmuran Cabang Hankam Bekasi akan meningkat atau sebaliknya, dengan asumsi lingkungan kerja tidak berubah.

\section{Pembahasan}

\section{Pengaruh Lingkungan Kerja dan Motivasi Kerja Terhadap Kinerja Karyawan}

Berdasarkan hasil dalam penelitian ini diduga lingkungan kerja dan motivasi kerja mendorong peningkatan kinerja karyawan. Dengan demikian, semakin baik Lingkungan Kerja dan Motivasi kerja terhadap kinerja karyawan yang diterapkan pada PT Bintang Kemakmuran Cabang Hankam-Bekasi, maka akan semakin meningkat pula kinerja karyawannya. Penelitian ini sesuai dengan penelitian terdahulu yang dilakukan oleh Gardjito, et al, (2014) yaitu pengaruh motivasi kerja dan lingkungan kerja terhadap kinerja karyawan.

\section{Pengaruh Lingkungan Kerja Terhadap Kinerja Karyawan}

Berdasarkan hasil dalam penelitian ini diduga Lingkungan Kerja yang baik dapat meningkatkan kinerja karyawan. Dengan demikian, semakin baik Lingkungan Kerja yang diterapkan pada PT Bintang Kemakmuran Cabang Hankam Bekasi, maka akan kuat pula peningkatan kinerja karyawannya. Penelitian ini sesuai dengan penelitian terdahulu yang telah dilakukan oleh Rahmawanti, et al (2014) yaitu pengaruh lingkungan kerja terhadap kinerja karyawan.

\section{Pengaruh Motivasi Kerja Terhadap Kinerja Karyawan}

Berdasarkan hasil dalam penelitian ini diduga motivasi kerja yang tinggi dapat mendorong peningkatan kinerja karyawan. Dengan demikian, semakin baik motivasi kerja yang diterapkan pada PT Bintang Kemakmuran Cabang Hankam Bekasi, maka semakin kuat pula kinerja karyawannya. Penelitian ini sesuai dengan penelitian terdahulu yang telah dilakukan oleh Kiruja dan Elegwa. (2013) yaitu pengaruh motivasi kerja terhadap kinerja karyawan.

\section{KESIMPULAN DAN SARAN}

\section{Kesimpulan}

Berdasarkan hasil penelitian dan analisis yang telah dilakukan mengenai pengaruh lingkungan kerja dan motivasi kerja terhadap kinerja karyawan pada PT Bintang Kemakmuran Cabang Hankam Bekasi maka dapat ditarik beberapa kesimpulan sebagai 
berikut: 1). Lingkungan kerja dan motivasi kerja secara simultan memiliki pengaruh dalam meningkatkan kinerja karyawan. 2). Lingkungan kerja berperan dalam meningkatkan kinerja karyawan. 3). Sistem motivasi kerja memiliki pengaruh dalam meningkatkan kinerja karyawan.

\section{Saran}

Berdasarkan hasil penelitian, maka dapat dikemukakan saran-saran sebagai berikut: 1). Pimpinan harus selalu memperhatikan lingkungan kerja dan motivasi kerja seluruh karyawan perusahaan. Karna berdasarkan hasil penelitian yang dilakukan lingkungan kerja, motivasi kerja dan kinerja karyawan merupakan sesuatu yang saling mempengaruhi. 2). Sebaiknya lingkungan kerja pada PT Bintang Kemakmuran Cabang Hankam Bekasi perlu diperhatikan dan ditingkatkan seperti pencahayaan dalam ruangan, karena lingkungan kerja mampu memberikan pengaruh dalam meningkatkan motivasi kerja dan kinerja karyawan. Pimpinan PT Bintang Kemakmuran Cabang Hankam Bekasi perlu meningkatkan motivasi kerja karyawan agar dapat lebih meningkatkan kinerjanya. Dengan cara memotivasi untuk karyawan berprestasi dengan memberikan imbalan atau pujian yang sesuai bila prestasi karyawan baik, sehingga karyawan akan merasa dihargai kerjanya.

\section{DAFTAR PUSTAKA}

Arikunto, Suharsimi. 2012. Prosedur Penelitian: suatu Pendekatan Praktik. Cetakan Ketigabelas. Jakarta: PT. Rineka Cipta.

Gardjito, Aldo Herlambang., Al Musadieq dan Eko, Gunawan . 2014. Pengaruh Motivasi Kerja Dan Lingkungan Kerja Terhadap Kinerja Karyawan" pada (Studi Karyawan Bagian Produksi PT. Karmand Mitra Andalan Surabaya). Jurnal Administrasi Bisnis Volume 13 Nomor 1, Agustus 2014. Hal. 1-8.

Ghozali, Imam, 2016. Aplikasi Analisis Multivariat dengan Program IBM SPSS 23. Edisi 8. Cetakan ke VIII. Semarang: Badan Penerbit Universitas Diponegoro.

Hasibuan, Malayu S. P. 2013. Manajemen Sumber Daya Manusia. Jakarta. PT. Bumi Aksara.

Kiruja, E K dan Elegwa, Mukuru. 2013. Effect of Motivation on Employee Performance In Public Middle Level Technical Training Institutions In Kenya. Internatioanl Journal of Advance in Management and Economics. July-Aug. 2013. Page. 73-82. ISN:22783369.

Mangkunegara, Anwar Prabu. 2017. Manajemen Sumber Daya Manusia Perusahaan. Bandung. Remaja Rosda Karya.

Rahmawanti, Nela Pima., Swasto, Bambang dan Prasetya, Arik. 2014. Pengaruh Lingkungan Kerja Terhaap Kinerja Karyawan Kantor Pelayanan Pajak Pratama Malang Utara. Jurnal Administrasi Bisnis Vol. 8 No. 2 Maret 2014, hal. 1-.9.

Sedarmayanti. 2015. Sumber Daya Manusia dan Produktivitas Kerja. Jakarta: Mandar Maju.

Sugiyono. 2017. Metode Penelitian Bisnis (Pedekatan Kuantitatif F, Kualitatif Dan R\&D). Bandung: CV Alfabeta. 